\title{
Uncertainty Analysis for Distribution of Greenhouse Gases Concentration in Atmosphere
}

\author{
B. Luo ${ }^{1 *}$, Y. Y. Yin ${ }^{2}$, G. H. Huang ${ }^{1}$ and Y. F. Huang ${ }^{1}$ \\ ${ }^{1}$ Environmental Systems Engineering Program, Faculty of Engineering, University of Regina, Regina, SK S4S 0A2, Canada \\ ${ }^{2}$ Adaptation and Impacts Research Group, Environment Canada, Vancouver, and Sust. Dev. Res. Inst. of UBC, BC V6T 1Z2, Canada
}

\begin{abstract}
Spatial distribution of greenhouse gases (GHGs) concentration in the atmosphere is important in determining the atmosphere's radioactive absorbtion and global warming. Reducing uncertainties in understanding the spatial distribution of GHGs concentration in the atmosphere have particular meaning in climate modeling and projection of future climate scenarios. In this study, the vertical distribution of GHGs concentration in the atmosphere is deduced and the relevant uncertainty is analyzed by a fuzzy set method. This method was applied in a case study to examine the vertical distribution of $\mathrm{CO}_{2}$ concentration in the atmosphere. Results indicate that uncertainties in projection of GHGs emissions and global surface temperature have played important roles on vertical distribution of $\mathrm{CO}_{2}$ concentration in the atmosphere. This has particular meaning for study of relation between $\mathrm{CO}_{2}$ distribution and global warming.
\end{abstract}

Keywords: $\mathrm{CO}_{2}$, concentration, distribution, fuzzy set theory, greenhouse gases, uncertainty

\section{Introduction}

The IPCC Third Report suggested that human activities have been the dominant detectable influence on climate change in the past century through buildup of GHGs in the atmosphere, (Houghton et al., 2001). Research showed that distributions of GHGs concentration in atmosphere had great influences on global climate system (Murphy \& Michell, 1995; Hu \& Bengtsson, 2000; Makar'eva \& Goshkov, 2001). In general circulation models (GCMs), spatial distribution of GHGs is the key input in modeling process, and they are always measured with monitored networks. For example, atomospheric $\mathrm{CO}_{2}$ monitoring network has been widely used to infer the latitudinal location and strength of $\mathrm{CO}_{2}$ sources and sinks (Keeling et al., 1989; Tans et al., 1990; Ciais et al., 1995). Since future distribution of GHGs concentration in the atmosphere cannot be measured, research approaches to project such distribution are regulated in climate change studies.

Previous studies indicate that inherent uncertainties in climate system can reduce GCMs' accuracy in future climate scenarios development (Shackley et al., 1998). One of the important uncertain factors affecting such distribution is projected anthropogenic GHGs emissions, which have major contributions to the GHGs concentration in the atmosphere. In addition, the increased global air temperature driven by human-induced GHGs emissions can also affect the spatial distribution of GHGs concentration in the atmosphere. Such dynamic interactions between GHGs concentration and transient global air temperature can further complicate the climate

\footnotetext{
* Corresponding author: luobi111@uregina.ca
}

modeling efforts. Moreover, the relations between spatial distribution of GHGs concentration, projected emissions, and global air temperature are always nonlinear instead of linear. In this respect, how to measure the degree of uncertainty generated from changes in global air temperature and GHGs emissions is critical in climate change modeling.

The fuzzy set theory, firstly introduced by Zadeh (1965), is a powerful tool for uncertainty analysis, which has been successfully applied in risk assessment, environmental modeling, and engineering systems (Bogardi et al., 1987; Bardossy \& Disse, 1993; Klir, 1997; Sasikumar \& Mujumdar, 1998; Chen et al., 2003). The fuzzy set approach has advantage in describing the uncertainties with a non-probabilistic framework. It also can handle the uncertainties in a direct way without requiring a large number of realizations, as well as deal with the membership or non-membership of an object in a set with imprecise boundaries. By constructing different membership functions, the fuzzy set theory can quantify linear and nonlinear relations between uncertain system inputs and outputs.

This study attempts to deduce the spatial distribution of GHGs concentration in the atmosphere based on kinetics theory, and to analyze the relevant uncertainty by fuzzy set theory. The Boltzamann distribution, which is widely used in statistical physics to describe dynamics in ideal gas movement, is used in this study to deduce the vertical distribution of GHGs concentration in the atmosphere. The vertex and Weibull distribution are applied to construct membership functions in the fuzzy set approach. In this paper, the distribution of GHGs concentration in the atmosphere is discussed in Section 2. The uncertainty analysis is described in Section 3. 
Section 4 presents a hypothetical case study to test the proposed methodology in applying the distribution of $\mathrm{CO}_{2}$ concentration in the atmosphere. Results are discussed in Section 5 , and then followed Sections 6 as conclusion.

\section{Distribution of GHGs Concentration in Atmosphere}

In perfect gases, it can be assumed that a distribution of molecules can be approached, which represents that an equilibrium state after complete random motion has set in and the velocities have reached their permanent regime. The mathematical formula to represent this phenomenon was deduced by Boltzmann and Maxwell (Loed, 1971). Assuming that the air molecules are rigid elastic spheres, number of air molecules within volume $d x d y d z$ can be expressed as follow (Loed, 1971).

$$
d N=\int_{-\infty}^{+\infty} \int_{-\infty}^{+\infty} \int_{-\infty}^{+\infty} e^{-\alpha} e^{-\frac{1}{k T}\left(\frac{p_{x}^{2}}{2 m}+\frac{p_{y}^{2}}{2 m}+\frac{p_{z}^{2}}{2 m}+\Phi\right)} d x d y d z d p_{x} d p_{y} d p_{z}
$$

where $d N$ is the total number of molecules within volume $d x d y d z ; e^{-\alpha}$ is a probability constant on condition of the initial condition of air; $k$ is the Boltzamann constant $(\mathrm{k}=$ $\left.1.3806503 \times 10^{-23} \mathrm{~m}^{2} \mathrm{~kg} \mathrm{~s}^{-2} \mathrm{~K}^{-1}\right) ; T$ is the absolute temperature of air; $p_{x}, p_{y}$ and $p_{z}$ represent momentum of air molecule in $x$-, $y$-, $z$ - axis direction, respectively; $m$ is average mass of air molecule within volume $d x d y d z ; \Phi$ is the potential of air molecule, which is a function of height $\mathrm{z}$. Integrating formula (1), the total number of air molecules within volume $V$ is:

$$
N=\iiint_{V} e^{-\alpha} \int_{-\infty}^{+\infty} \int_{-\infty}^{+\infty} \int_{-\infty}^{+\infty} e^{-\frac{1}{k T}\left(\frac{p_{x}^{2}}{2 m}+\frac{p_{y}^{2}}{2 m}+\frac{p_{z}^{2}}{2 m}+\Phi\right)} d x d y d z d p_{x} d p_{y} d p_{z}
$$

Since changes in kinetic and potential of air molecules are continuous according to the change of elevation, it can be assumed that $n(x, y, z) d x d y d z$ represents the total number of air molecules with different velocities distributed in the coordinate space from $x$ to $x+d x, y$ to $y+d y$, and $z$ to $z+d z$. Thus, the total number of air molecules in this volume can be expressed as follow:

$N=\iiint_{V} n(x, y, z) d x d y d z$

Compared formula (2) with (3), we can get:

$n(x, y, z)=e^{-\alpha} \int_{-\infty}^{+\infty} \int_{-\infty}^{+\infty} \int_{-\infty}^{+\infty} e^{-\frac{1}{k T}\left(\frac{p_{x}^{2}}{2 m}+\frac{p_{y}^{2}}{2 m}+\frac{p_{z}^{2}}{2 m}+\Phi\right)} d p_{x} d p_{y} d p_{z}=n_{o} e^{-\frac{\Phi}{k T}}$

where $n_{\circ}=e^{-\alpha} \cdot(2 \pi m k T)^{3 / 2}$, which represents the number of air molecules in unit volume when potential is zero. Since the molecule number density of air can be expressed as $\rho=n m$, the vertical distribution of air density can be expressed as:

$\rho=\rho_{o} e^{-\frac{\Phi}{k T}}$

where $\rho_{\circ}$ represents air density where potential $\Phi$ is zero (ground level).

As compounds of the atmosphere, percentages of GHGs are lower compared to percentages of two major air compounds, oxygen and nitrogen. Since the molecule weights of GHGs are different from oxygen and nitrogen, the vertical distribution of one particular greenhouse gas's concentration is actually different from the vertical distribution of air. However, it is reasonable to assume that their distributions are similar in some cases. Then, the vertical concentration distribution for that particular greenhouse gas in atmosphere can be expressed as:

$C_{h}=C_{o} e^{-\frac{\Phi}{k T}}=C_{o} e^{-\frac{m(g) g h}{k T}}$

where $\mathrm{C}$ is the concentration of that particular greenhouse gas at height $h ; C_{0}$ represents its concentration when its potential is zero (ground level); $m(g)$ is the molecule mass of that particular greenhouse gas; $g$ is gravity constant; $h$ is height above ground level.

According to formula (6), it shows that the vertical concentration distribution of that greenhouse gas is also a function of air temperature $T$. Studies show that the variability of surface air temperature proves to be very important for detecting anthropogenic climate change (Santer et al., 1995). In the troposphere, it can be assumed that air condition is obeyed to adiabatic condition. We then have the Lapse rate formula as follow (Wark, 1990).

$T=T_{o}-\frac{g m(a) h}{C_{p}}$

where $T_{0}$ is the surface air temperature; $m(a)$ is the molecule mass of air per mole $\left(29 \times 10^{-3} \mathrm{~kg}\right) ; C_{p}$ is the heat capacity of the air at constant pressure, which is equal to $3.5 \mathrm{R}(\mathrm{R}=8.31$ $\mathrm{m}^{2} \mathrm{~kg} \mathrm{~s}^{-2} \mathrm{~K}^{-1}$ ). Then, formula (6) can be transformed into the following expression:

$C_{h}=C_{o} e^{-\frac{m(g) g h}{k\left(T_{o}-g m(a) h / C_{p}\right)}}$

This is the vertical concentration distribution for a particular greenhouse gas in atmosphere. This distribution is related to not only its concentration at ground level, but also vertical 
distribution of air temperature.

\section{Uncertainty Analysis}

Fuzzy set theory has been successfully applied in uncertainty analysis during the past decades (Dou et al., 1997; Freissinet et al., 1999; Li et al., 2003; Chen et al., 2003). Contrary to the classical set theory that describes each element either belongs to or does not belong to a set, a fuzzy set is characterized by a membership function, which represents numerically the degree to which an element belongs.

The construction of membership functions is still a debatable issue in the fuzzy set theory (Kandel, 1986). There are only a few methods published in the fuzzy literatures to deal with construction of membership functions (Kandel, 1986; Turksen, 1991; Harris, 2000). The two major methods for deriving membership functions are the normative and the empirical approaches as reported by Turksen (1986). Two comm.only used membership function for characterizing fuzzy numbers are triangular functions (linear) and bounded bellshape (nonlinear) function. Both of these methods will be used in this study to analyze the uncertainty in distribution of GHGs concentration in atmosphere.

According to formula (8), those two inputs, the projected GHGs concentration in ground level and surface air temperature, are uncertain in future. Though it is hard to project their deterministic values, their maximum, minimum, and mean values can be estimated. Thus, the upper and lower threshold values of surface concentration and temperature can be projected within a period of time in the future. Considering the relation between GHG emissions and its concentration at ground level is monotone, we can assume that the membership function used to represent uncertainty in surface GHGs concentration is linear. Thus, the vertex method can be used here to construct the membership function. According to Dong et al. (1985), the membership function can be expressed as follow:

$$
\mu_{(A)}(C)=\left\{\begin{array}{cc}
0, & C_{o}<C_{o}^{-} \\
\frac{C_{o}-C_{o}^{-}}{\overline{C_{o}}-C_{o}}, & C_{o}^{-} \leq C_{o} \leq \bar{C}_{o} \\
1, & C_{o}=\bar{C}_{o} \\
\frac{C_{o}^{+}-C_{o}}{C_{o}^{+}-\bar{C}_{o}}, & \bar{C}_{o} \leq C_{o} \leq C_{o}^{+} \\
0, & C_{o}<C_{o}^{+}
\end{array}\right.
$$

where $\mu_{A}(C)$ is the fuzzy set value of concentration for one particular greenhouse gas at ground level, which is from 0 to $1 ; \bar{C}_{\text {。 }}$ is the mean value of the GHG's concentration at ground level; $C_{\circ}^{-}$and $C_{\circ}^{+}$represents lower and upper values of concentration at ground level, respectively.
Because of the dynamic linkage between air temperature and GHGs emissions, prediction of future air temperature is more challenge. Then, the membership function used to express fuzziness in air temperature is far from linear and should be represented as nonlinear. Recent studies show that the Weibull distribution is a good method to quantify nonlinearity in fuzzy set approach (Butkiewicz, 1996; Harris, 2001). This distribution will be used here to construct the membership function to identify the uncertainty in surface air temperature change. The membership function can be expressed as:

$\mu_{A}\left(T_{o}\right)=\left\{\begin{array}{cc}0, & T_{o}<j-b \\ \frac{b^{2}-\left(T_{o}-j\right)^{2}}{b^{2}} \cdot e^{\frac{-\left(T_{o}-j\right)^{2}}{2 \sigma^{2}}}, & j-b \leq T_{o} \leq j+b \\ 0, & T_{o}>j+b\end{array}\right.$

where $\mu_{A}\left(T_{\circ}\right)$ is the fuzzy set value for future surface air temperature with values from 0 to $1 ; \mathrm{T}_{0}$ is the value of future surface air temperature; $\varphi$ is the mean value of surface air temperature; $\sigma$ is the standard deviation of this distribution; $b$ is the interval parameter in this distribution.

\section{Case Study}

\subsection{Overview of the Study System}

The following hypothetical case about vertical distribution of $\mathrm{CO}_{2}$ concentration was conducted to test the above introduced methodology. Carbon dioxide is one of the primary greenhouse gases. According to different projected scenarios of future GHGs emissions, it is estimate that the average global surface $\mathrm{CO}_{2}$ concentration by year 2100 will be $30-150 \%$ higher than today's levels in the absence of emissions control policies (Houghton et al., 2001). In such circumstances, the average global surface concentration of $\mathrm{CO}_{2}$ in year 2100 will be at levels ranging from $468 \mathrm{ppm}$ to $900 \mathrm{ppm}$. By 2100, further increases of greenhouse gases in the atmosphere are expected to increase the global average surface temperature by about $1.4-5.8^{\circ} \mathrm{C}$, with significant regional variation (Houghton et al., 2001). In this study, we assume that the average surface temperature is around $30^{\circ} \mathrm{C}$ near equator currently and it will increase $2-6^{\circ} \mathrm{C}$ in year 2100 . The problem under consideration is to analyze the uncertainty of vertical distribution of $\mathrm{CO}_{2}$ concentration in the atmosphere near equator. Table 1 lists current values of surface $\mathrm{CO}_{2}$ concentration and average surface air temperature are listed. Without loss of generality, this study will only analyze $\mathrm{CO}_{2}$ concentration at height of $0.5 \mathrm{~km}, 5 \mathrm{~km}$, and $10 \mathrm{~km}$.

\subsection{Results and Discussions}

According to formula (9) and (10), the $\mu$-cut values for the $\mathrm{CO}_{2}$ concentration at ground level and surface air temperature are illustrated in Figure 1 and 2, respectively. By taking each end point from the interval values of parameter $C_{\circ}^{ \pm}$and $T_{\circ}^{ \pm}$, the end points can be combined into a nary array 
for each $\mu$-cut value. Using formula (7) and (8), a nary array of finale interval values of $\mathrm{CO}_{2}$ concentration for each $\mu$-cut value can be calculated, which is illustrated in Figure 3. Here, Figure 3 only illustrates such values when $\mu$-cut value is equal to $0,0.2,0.4,0.6,0.8$, and 1 , respectively. The results show that nearly $98 \%$ of $\mathrm{CO}_{2}$ is concentrated in the space within $10 \mathrm{~km}$ above ground. It means that the increased $\mathrm{CO}_{2}$ is mainly concentrated in the low troposphere. Solutions also indicate that the imprecision depicted in the output is directly related to the level of credibility, or degree of confidence, as determined by the $\mu$ values, as well as estimation of input parameters and the number of the parameters. If one wishes to interpret the results with a "higher degree of confidence", then one may select a $\mu$ at values greater than zero.

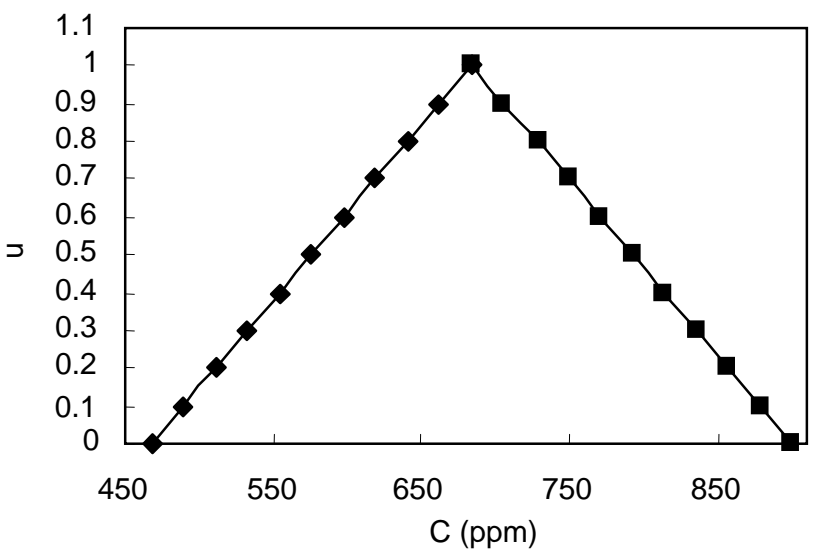

Figure 1. $\mu$-cut values for surface $\mathrm{CO}_{2}$ concentration near equator by year 2100 .

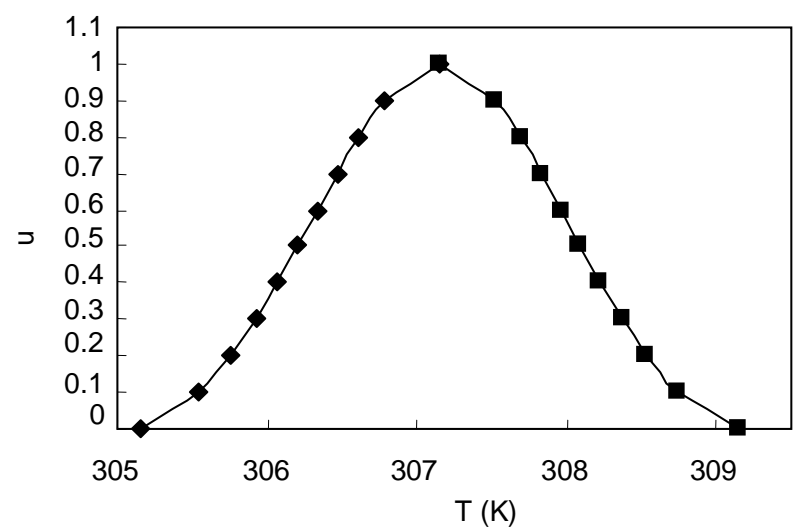

Figure 2. $\mu$-cut values for surface air temperature near equator by year 2100 .

Sensitivity analysis can also be done here to measure which input the vertical $\mathrm{CO}_{2}$ distribution is more sensitivity to. This can be approached by getting partial differential values of $\partial C / \partial C_{0}$ and $\partial C / \partial T_{0}$ in each position. Assuming that the surface air temperature and $\mathrm{CO}_{2}$ concentration are deterministic by given their mean values, $\mathrm{CO}_{2}$ concentration in each position can be worked out as listed in Table 2. Results show that the vertical distribution of $\mathrm{CO}_{2}$ concentration is more sensitive to surface temperature.

Table 1. Future $\mathrm{CO}_{2}$ Concentration (ppm) and Air Temperature $(\mathrm{K})$ at Ground Level

\begin{tabular}{|c|c|c|c|c|c|}
\hline $\begin{array}{l}\text { Boundary } \\
\text { value of } \mathrm{CO}_{2} \\
\text { concentration } \\
C_{\circ}^{ \pm}\end{array}$ & $\begin{array}{l}\text { Average } \\
\text { value of } \mathrm{CO}_{2} \\
\text { concentration } \\
\bar{C}\end{array}$ & $\begin{array}{l}\text { Air temper- } \\
\text { ature at ground } \\
\text { level } T_{\circ}^{ \pm}\end{array}$ & $\varphi$ & $\sigma$ & $b$ \\
\hline$[468,900]$ & 684 & {$[305.2,309.2]$} & 307.2 & 1 & 2 \\
\hline
\end{tabular}

Table 2. Sensitivity Analysis of $\mathrm{CO}_{2}$ Concentration and Air Temperature

\begin{tabular}{lllll}
\hline $\mathrm{T} 0=307.2(\mathrm{~K})$ & $\mathrm{h}=0$ & $\mathrm{~h}=0.5 \mathrm{~km}$ & $\mathrm{~h}=5 \mathrm{~km}$ & $\mathrm{~h}=10 \mathrm{~km}$ \\
\hline $\mathrm{Ch}(\mathrm{ppm})$ & 684 & 408.06 & 1.62 & $2.29 \mathrm{E}-04$ \\
$\partial C_{h} / \partial C_{0}$ & 1 & 0.597 & 0.00237 & $3.35 \mathrm{E}-07$ \\
$\partial C_{h} / \partial T_{0}$ & 1 & 0.697 & 0.03799 & $1.64 \mathrm{E}-05$ \\
\hline
\end{tabular}

The results indicate that the initial inexact inputs have great impacts on vertical distribution of $\mathrm{CO}_{2}$ concentration in atmosphere. This can eventually affect the precision of climate modeling. However, the surface $\mathrm{CO}_{2}$ concentration has huge variations in different locations on the earth. Such variations should be considered when applying the proposed method in climate modeling process. In addition, since the molecule weight of $\mathrm{CO}_{2}$ is larger than $\mathrm{N}_{2}$ and $\mathrm{O}_{2}$, the vertical distribution of $\mathrm{CO}_{2}$ concentration in atmosphere actually is different from the vertical distribution of air density. This implies that the assumption of same distribution between vertical $\mathrm{CO}_{2}$ concentration and vertical air density is not realistic. Thus, the vertical distribution of $\mathrm{CO}_{2}$ concentration in atmosphere should be revised in further studies. However, the proposed method for analyzing uncertainty in distribution of GHGs concentration is a promising one for quantifying uncertainties in climate modeling. By adding a degree of confidence on the results (a certain $\mu$ values), it can provide more meaningful modeling results.

\section{Conclusions}

This paper presents a study in explaining the vertical distribution of GHGs concentration in the atmosphere and the relevant uncertainty. The developed method was applied in a case study. Two parameters, the average surface $\mathrm{CO}_{2}$ concentration and surface air temperature near equator in year 2100 , were used as inexact inputs in uncertainty analysis. The triangular function and Weibull distribution were applied to construct the membership functions for treating such inexact inputs. It indicates that the method based on fuzzy set theory is effective for uncertainty analysis. Results of the case study 


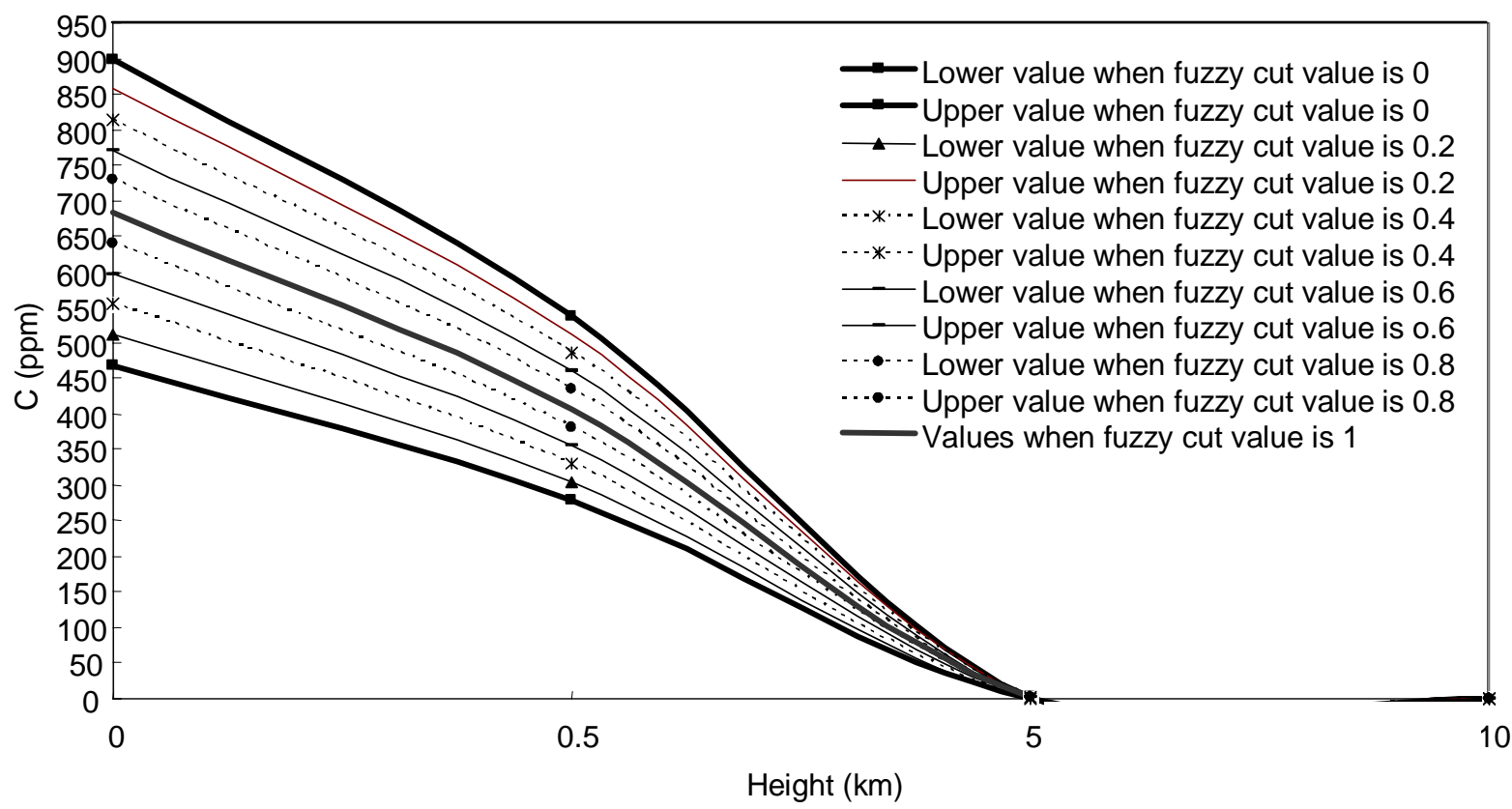

Figure 3. Final interval values of $\mathrm{CO}_{2}$ concentration in different height.

indicate that projection of GHGs emissions has significant influence on spatial distribution of GHGs in the atmosphere and eventually affects the precision of climate modeling results.

\section{References}

Bardossy, A. and Disse, M. (1993). Fuzzy rule-based models for infiltration. Water Resour. Res., 29(2), 373-382.

Bogardi, I., Duckstein, L. and Bardossy, A. (1987). Uncertainty in environmental risk analysis, in Y.Y. Haimes and E.Z. Stakhiv (Eds.), Risk Analysis and Management of Natural and Manmade Hazards, ASCE, New York, 154-170.

Butkiewicz, B.S. (1996). Fuzzy Weibull distribution, its definition and application to reliability prediction. Circuit Theory Electron. Circuits, 1, 183-188.

Chen, Z., Huang, G.H. and Chakma, A. (2003). FUSRA: A Hybrid Fuzzy-Stochastic Approach for Assessing Health Risks from Contaminated Groundwater Systems. J. Environ. Eng. (American Society of Civil Engineers), 129, 79-88.

Ciais, P., Tans, P.P., White, J.W.C., Trolier, M., Francey, R.J., Berry, J.A., Randall, D.R., Sellers, P.J., Collatz, J.G. and Schimel, D.S. (1995). Partitioning of ocean and land uptake of $\mathrm{CO}_{2}$ as infeered by $\delta 13 \mathrm{C}$ measurements from the NOAA/CMDL global air sampling networks. J. Geophys. Res., 100, 5051-5070.

Dong, W.M., Shah, H.C. and Wong, F.S. (1985). Fuzzy computations in risk and decision analysis. Civil Eng. Syst., 2, 201-208.

Dou, C., Woldt, W., Bogardi, I. and Dahab, M. (1997). Numerical solute transport simulation using fuzzy sets approach. J. Contam. Hydrol., 27, 107-126.

Freissinet, C., Vauclin, M. and Erlich, M. (1999). Comparison of first-order analysis and fuzzy set approach for the evaluation of imprecision in a pesticide groundwater pollution screening model. J. Contam. Hydrol., 37, 21-43.
Harris, J. (2000). An Introduction to Fuzzy Logic Application, Kluwer Academic Publishers, Dordrecht, Holland.

Harris, J. (2001). Piecewise linear reliability data analysis with fuzzy sets, in Proc. of the I MECH E Part C J. Mech. Eng. Sci., 1075-1082.

Houghton, J.T. et al. (2001). Climate Change 2001: The Scientific Basis (Cambridge Univ. Press, Cambridge, 2001). http:// www. ipcc.ch/ (accessed May, 2004).

$\mathrm{Hu}, \mathrm{Z} . Z$. and Bengtsson, L. (2004). Stratospheric response to global warming in the Northern Hemisphere winter. Tellus A, 56(2).

Kandel, Abraham (1986). Fuzzy Mathematical Techniques with Applications / Abraham Kandel, Mass., Addison-Wesley.

Keeling, C.D., Piper, S.C. and Heimann, M. (1989). A three dimensional transport model for atmospheric $\mathrm{CO}_{2}$ (4): Mean annual gradients and inter-annual variations, $A G U$ Monograph 55, Washington, American Geographical Union, 305-362.

Klir, G.J. (1997). The role of constrained fuzzy arithmetic in engineering, in B.M. Ayyub and M.M. Gupta (Editors), Uncertainty Analysis in Engineering and Sciences: Fuzzy Logic, Statistics, and Neural Network Approach, Kluwer Academic Publishers, Norwell, MA, 1-19.

Li, J.B., Chakma, A., Zeng, G.M. and Liu, L. (2003). Integrated fuzzy-stochastic modeling of petroleum contamination in subsurface. Energy Sour., 25(6), 547-563.

Loed, L.B. (1971). The Kinetic Theory of Gases, Dover publications, INC, New York.

Makar'eva, A.M. and Goshkov, V.G. (2001). The greenhouse effect and the stability of the global mean surface temperature. Doklady Earth Sci., 377(2), 210-214, translated from Doklady Akademii Nauk, 376(6), 810-814.

Murphy, J.M. and Mitchell, J.F.B. (1995). Transient response of Hadley Centre coupled ocean-atmosphere model to increasing carbon dioxide, Par II: spatial and temporal structure of response. $J$. 
Clim., 8, 57-80.

Santer, B.D., Taylor, K.E., Penner, J.E., Wigley, T.M.L., Cubasch, U. and Jones, P.D. (1995). Towards the detection and attribution of an anthropogenic effect on climate. Clim. Dyn., 12, 77-100.

Sasikumar, K. and Mujumdar, P.P. (1998). Fuzzy optimization model for water quality management of a river system. J. Water Resour. Plann. Manage., 124(2), 79-88.

Shackley, S., Young, P., Parkison, S. and Wynne, B. (1998). Uncertainty, complexity and concepts of good science in climate change modeling: are GCMs the best tools?, Clim. Change, 38,
159-205.

Tans, P.P., Fung, I.Y. and Takahashi, T. (1990). Observational constraints on the global atmospheric $\mathrm{CO}_{2}$ budget. Sci., 247, 1431-1438.

Turksen, I.B. (1991). Measurement of membership functions and their acquisition. Fuzzy Sets Syst., 40(1), 5-34.

Wark, Kenneth and Warner, C.F. (1990). Air Pollution-Its Origin and Control, second edition, New York, NY, Harper Collins publishers.

Zadeh, L.A. (1965). Fuzzy sets, Inf. Control, 8, 338-353. 